\title{
CAMINHOS PARA A FORMULAÇÃO DE UMA POLÍTICA PÚBLICA DE ACOMPANHAMENTO DE EGRESSOS DO ENSINO SUPERIOR
}

\author{
http://dx.doi.org/10.5902/2318133847089
}

\author{
Lilian Wrzesinski Simon ${ }^{1}$ \\ Andressa Sasaki Vasques Pacheco²
}

\begin{abstract}
Resumo
O acompanhamento de egressos fornece uma série de mecanismos para elevar a qualidade do ensino superior ao conectar a universidade com as demandas da sociedade e do mundo do trabalho. Neste artigo apresenta-se o acompanhamento de egressos do ensino superior, visando a sua identificação como uma política pública de avaliação educacional. Os marcos regulatórios da educação superior, associados às experiências internacionais de acompanhamento de graduados e às práticas institucionais adotadas em universidades brasileiras, evidenciam que 0 acompanhamento de egressos ainda precisa ser consolidado como instrumento de avaliação institucional. Para a sua concretização necessita-se o envolvimento dos gestores e das instâncias governamentais do segmento educacional.

Palavras-chave: egressos; educação superior; avaliação institucional.
\end{abstract}

\section{PATHS FOR THE FORMULATION OF A PUBLIC POLICY FOR FOLLOW-UP ON HIGHER EDUCATION}

\begin{abstract}
The monitoring of graduates provides a series of mechanisms to raise the quality of higher education by connecting the university with the demands of society and the world of work. This research presents the monitoring of graduates from higher education, aiming at their identification as a public educational evaluation policy. The regulatory frameworks of higher education, associated with the international experiences of monitoring graduates and the institutional practices adopted in Brazilian universities, show that the monitoring of graduates still needs to be consolidated as an institutional assessment tool. For its realization, there is a long way, which involves the involvement of managers and government bodies in the educational segment.

Key-words: graduates; higher education; institutional evaluation.
\end{abstract}

1 Universidade Federal de Santa Catarina, Brasil. E-mail: lilian.uffs@gmail.com.

2 Universidade Federal de Santa Catarina, Brasil. E-mail: andressa.ufsc@gmail.com.

Regae: Rev. Gest. Aval. Educ. Santa Maria v. 9 n. 18 Pub. contínua 2020 p. $1-17$ 


\section{Introdução}

acompanhamento de egressos é um importante instrumento de avaliação dos resultados da ação formativa das instituições de ensino superior. Com a adoção do Sistema Nacional de Avaliação da Ensino superior - Sinaes - a avaliação dos egressos passou a ser um dos indicadores de qualidade do ensino superior (Brasil, 2004). Desde então o sistema educacional brasileiro passou a inserir os egressos entre o público alvo da avaliação institucional por meio de políticas e ações institucionais de acompanhamento de egressos (Inep, 2015).

Contudo, o estabelecimento de ações de acompanhamento de egressos depende da iniciativa de cada instituição, ao passo que alguns sistemas educacionais internacionais já contam com estrutura, sistemas informatizados e metodologias integradas para a coleta de informações sobre os egressos em nível interinstitucional e nacional (Paul, 2015; Almeida; Chaves, 2015).

De acordo com o Censo da Ensino superior o número de concluintes tem aumentado gradativamente na última década: "Em 2018 mais de um milhão e duzentos mil estudantes concluíram ensino superior de graduação no Brasil” (Inep, 2019, p. 30). Esse aumento está associado especialmente às políticas de expansão e democratização do ensino superior no país, que ampliaram a quantidade de cursos e vagas nas IES brasileiras, permitindo o acesso ao ensino superior a uma parcela maior da população (Ristoff, 2016; Paula, 2017). Entretanto, cabe destacar que o aumento do número de concluintes se deve a uma elevação ainda maior do número de ingressantes, de modo que há uma razão desproporcional entre a evolução do número de ingressantes e concluintes. Essa razão desproporcional é explicada pelos índices crescentes de evasão observados nos últimos anos no ensino superior (Paula, 2017).

A avaliação do ensino superior é um dos instrumentos disponíveis para a gestão universitária verificar os resultados das políticas adotadas e propor melhorias nos processos acadêmicos e administrativos (Baggi; Lopes, 2011; Ristoff, 2013). Por meio da avaliação institucional é possível assegurar a qualidade da formação ofertada pelos sistemas de ensino e antecipar medidas de controle da evasão dos alunos (Baggi; Lopes, 2011). Nesse sentido, "as informações prestadas pelos egressos [...] são fundamentais na concretização de um processo avaliativo que consolide as qualidades da instituição, a busca constante por melhor qualidade e o atendimento das expectativas da sociedade" (Silva; Bezerra, 2015, p.14).

$\mathrm{Na}$ França, Alemanha e os Estados Unidos da América, por exemplo, o acompanhamento da inserção profissional dos egressos é um tema de elevada importância para a avaliação do sistema educacional (Paul, 2015). As ações desenvolvidas nesses países podem trazer contribuições que, com as devidas adaptações, poderão auxiliar na concepção do acompanhamento de egressos do ensino superior como uma política pública.

\section{Marcos regulatórios, políticas e diretrizes do ensino superior brasileiro}

No texto da Constituição Federal de 1988, no artigo 205, a educação é concebida como direito de todos e dever do Estado e da família, com a colaboração e o incentivo da sociedade tendo, entre outras funções, o pleno desenvolvimento da pessoa, seu preparo para o exercício da cidadania e sua qualificação para o trabalho. Entre os princípios 
elencados no artigo 206 para o ensino estão: a igualdade de condições para o acesso e permanência; a liberdade de aprender, ensinar, pesquisar e divulgar o pensamento, a arte e o saber; o pluralismo de ideias, de concepções pedagógicas e a coexistência de instituições públicas e privadas de ensino; a gratuidade do ensino público em estabelecimentos oficiais; a valorização dos profissionais da educação; a gestão democrática do ensino público; a garantia de padrão de qualidade; e a garantia do piso salarial profissional nacional para os profissionais da educação pública (Brasil, 1988).

Consoante o artigo 207 da Constituição de 1988, as universidades e as instituições de pesquisa científica e tecnológica gozam de autonomia didático, científica, administrativa e de gestão financeira e patrimonial, obedecem ao princípio de indissociabilidade entre ensino, pesquisa e extensão e podem admitir professores, técnicos e cientistas estrangeiros. $O \S 2^{\circ}$ do artigo 213 prevê ainda que as atividades de pesquisa, de extensão e de estímulo e fomento à inovação, realizadas por universidades ou por instituições de educação profissional e tecnológica, podem receber apoio financeiro do poder público (Brasil, 1988).

A lei n. 9.394, de 20 de dezembro de 1996, a LDB, no artigo $9^{\circ}$, preconiza que a União é responsável pela coleta, análise e disseminação de informações sobre a educação, assim como é por assegurar processo nacional de avaliação do rendimento escolar no ensino fundamental, médio e superior; em colaboração com os sistemas de ensino, objetivando a definição de prioridades e a melhoria da qualidade do ensino, baixar normas gerais sobre cursos de graduação e de pós-graduação e assegurar processo nacional de avaliação das instituições de educação superior, com a cooperação dos sistemas responsáveis por esse nível de ensino. $\mathrm{O}$ artigo 41 prevê que "o conhecimento adquirido na educação profissional e tecnológica, inclusive no trabalho, também poderá ser objeto de avaliação, reconhecimento e certificação para prosseguimento ou conclusão de estudos" (Brasil, 1996, s.p).

No artigo 43 da LDB prevê-se que a ensino superior tem por finalidade estimular a criação cultural e o desenvolvimento do espírito científico e do pensamento reflexivo; formar diplomados nas diferentes áreas de conhecimento, aptos para a inserção em setores profissionais e para a participação no desenvolvimento da sociedade brasileira; e colaborar na sua formação contínua. Conforme prevê o artigo 46, a autorização, o reconhecimento de cursos e o credenciamento de instituições de ensino superior terão prazos limitados, sendo renovados, periodicamente, após processo regular de avaliação (Brasil, 1996).

O Sinaes, instituído pela lei n. 10.861 , de 14 de abril de 2004, foi o primeiro sistema avaliativo que incluiu em seus indicadores a preocupação com o destino dos egressos (Brasil, 2004). Entretanto, cerca de uma década e meia após sua implantação a política de acompanhamento de egressos ainda não está consolidada no sistema educacional brasileiro, especialmente nas instituições públicas, que pouco investem em marketing de relacionamento com os ex-alunos para preservar os vínculos estabelecidos e coletar informações sobre os resultados das ações formativas (Almeida; Chaves, 2015).

Entre os instrumentos de produção de informações previstos na LDB e no Sinaes, cabe destacar o papel do Censo da Educação Superior, "instrumento de pesquisa mais completo do Brasil", que reúne informações sobre as IES, seus cursos, alunos e 
docentes. Entre os dados coletados anualmente estão a quantidade de vagas oferecidas, inscrições, matrículas, ingressantes, concluintes e docentes "nas diferentes formas de organização acadêmica e categoria administrativa" (Inep, 2020, s.p.).

Várias políticas públicas educacionais de expansão e democratização do acesso ao ensino superior sucederam a publicação da LDB, com destaque para os planos nacionais de educação, o Fundo de Financiamento Estudantil - Fies -, o Programa Universidade para Todos - Prouni -, o Programa de Apoio a Planos de Reestruturação e Expansão das Universidades Federais - Reuni - e o Programa Nacional de Assistência Estudantil Pnaes.

O PNE tem duração decenal com o objetivo de articular o sistema nacional de educação em regime de colaboração e de definir diretrizes, objetivos, metas e estratégias para assegurar a manutenção e o desenvolvimento do ensino em seus diversos níveis, etapas e modalidades, por meio de ações integradas por diferentes esferas federativas que conduzam à erradicação do analfabetismo; a universalização do atendimento escolar; a melhoria da qualidade do ensino; a formação para o trabalho; a promoção humanística, científica e tecnológica do país (Brasil, 1988).

Entre as metas do PNE 2014-2024, relacionadas com a qualidade do ensino superior e o desenvolvimento socioeconômico do país, estão a expansão da educação profissional e tecnológica; a elevação do número de matrículas da população de 18 a 24 anos ensino superior para $50 \%$ e a taxa líquida para 33\%; a ampliação da proporção de mestres e doutores no corpo docente em efetivo exercício para $75 \%$, sendo, no mínimo, $35 \%$, doutores; a elevação do número de matrículas na pós-graduação stricto sensu para suprir a necessidade de mestres e doutores que trabalham nos setores estratégicos da economia e para investir na formação dos profissionais que atuarão na educação básica (MEC, 2014).

As metas do PNE relacionadas ao ensino superior denotam a necessidade de avaliação de todo o ciclo formativo desde o ingresso até a retroalimentação do sistema, a exemplo dos diplomados que atuam profissionalmente como docentes na educação básica e gestores educacionais.

No que se refere à expansão do acesso observa-se um avanço maior nas políticas públicas. No âmbito das IES privadas o Fies, instituído pela lei n. 10.260, de 12 de julho de 2001, caracteriza-se pela oferta de financiamento público para os estudantes que não têm condições de pagar pelos seus estudos durante o período de formação acadêmica, ao passo que o Prouni, criado pela lei n. 11.096, de 13 de janeiro de 2005, prevê a concessão de bolsas de estudos para estudantes de baixa renda poderem ingressar em cursos de graduação.

No sistema público federal, o Reuni, regulamentado pelo decreto n. 6.096, de 24 de abril de 2007, teve como objetivo criar condições para a ampliação do acesso e permanência na educação superior, no nível de graduação, bem como elevar a taxa média de conclusão dos cursos presenciais de graduação para noventa por cento e da relação de alunos de graduação por professor para dezoito, num prazo de cinco anos (Brasil, 2007).

Assegurar a efetividade das políticas de ampliação do acesso tornou-se um dos desafios da gestão universitária, que buscou alinhar estratégias para viabilizar a permanência dos estudantes no campus. O Pnaes, regulamentado pelo decreto n. 7.234, 
de 19 de julho de 2010, possui os seguintes objetivos relacionados à permanência: democratizar as condições de permanência; minimizar os efeitos das desigualdades sociais e regionais; reduzir as taxas de retenção e evasão; e promover a inclusão social pela educação (Brasil, 2010).

Após o estabelecimento das políticas de assistência estudantil, houve ainda outras mudanças relacionadas a ampliação e democratização do acesso. A lei n. 12.711, de 29 de agosto de 2012, denominada Lei de cotas, consolidou o ingresso nas Ifes por meio das políticas de ações afirmativas, ao estabelecer diretrizes para a inclusão de estudantes de escolas públicas, de origem social menos favorecida e de extratos sociais historicamente discriminados na universidade. A aprovação dessa lei contribuiu para a elevação no número de ingressantes em condições de vulnerabilidade social nos cursos de graduação das IES públicas.

Esse processo perpassa por um alinhamento entre as políticas públicas de acesso e permanência. A ampliação do acesso concedeu o passe para a entrada de estudantes no sistema, mas não é garantia de que eles consigam se estabelecer no campus e concluir seus estudos no tempo esperado. Portanto, o desafio da gestão acadêmica se expressa na necessidade de avançar nas ações de permanência e êxito (Paula, 2017). A avaliação dos egressos é fundamental nesse processo, pois quem já percorreu esse caminho e enfrentou as dificuldades do percurso consegue vislumbrar aspectos importantes para 0 direcionamento dessas ações (Lousada; Martins, 2005).

Os egressos constituem uma fonte de informações que não pode ser ignorada no processo de avaliação, devido às possibilidades de identificarem aspectos que o ambiente interno não pode responder para a gestão (Lousada; Martins, 2005). Fomentar a participação dos egressos nos processos avaliativos é uma estratégia que já encontra-se difundida em sistemas educacionais internacionais como fonte de informações sobre o perfil profissional desejado pelo mercado de trabalho, os níveis de inserção profissional e a avaliação do ensino (Paul, 2015; Almeida; Chaves, 2015).

\section{Contribuições de experiências internacionais de acompanhamento de egressos para a construção de uma política pública de avaliação}

Conforme alegam Almeida e Chaves (2015), nos países europeus, tanto as instituições de ensino, quanto as esferas governamentais, têm se empenhado em acompanhar o destino dos graduados, tratando a matéria como uma questão social. $A$ necessidade de alinhamento entre a formação acadêmica e as demandas do mercado de trabalho, nos diferentes setores da economia, já era objeto de estudo na França nos anos de 1970 (Paul, 2015; Céreq, 2018). A evolução dos estudos sobre o tema foram fundamentais para o desenvolvimento de um sistema estatístico permanente para documentar com rigor o processo de inserção profissional dos egressos. As pesquisas com alunos e egressos também exercem o importante papel de alimentar o sistema com sugestões de melhorias da qualidade da educação e informações que evidenciam aspectos onde há necessidade de correção de distorções e defasagens (Incher-Kassel, 2018).

Além disso grande parte dos países desenvolvidos investiram intensamente em educação, formação e pesquisa. A Alemanha, por exemplo, foi precursora na criação de universidades de pesquisa que, posteriormente, se expandiu pela América, influenciando 
nações como os EUA. O sistema de ensino superior norte-americano, por sua vez, é um dos mais complexos e diferenciados do mundo, com instituições de funções e qualidade diversas, como os high colleges, as universidades de vários formatos e os centros de pesquisa (Terra, 2014). O acompanhamento de egressos é tradicional, sendo explorado como instrumento de avaliação, de planejamento e de marketing estratégico (Paul, 2015).

A análise das práticas internacionais de acompanhamento de egressos provoca reflexões sobre os caminhos que ainda precisam ser percorridos pelo Brasil (Paul, 2015; Almeida; Chaves, 2015). A experiência francesa de acompanhamento de egressos foi adotado como a principal referência nesta abordagem pela sua proximidade e pelo alinhamento que possui com a perspectiva de política pública de Estado. O exemplo da universidade alemã também possui diversos elementos a serem explorados, ao passo que o modelo norte-americano, devido a sua complexidade e heterogeneidade, apresenta maiores dificuldades de enquadramento na perspectiva de política pública, nos moldes que se pretende propor.

Do mesmo modo, os modelos europeus que integram consórcios internacionais não foram explorados pelas dificuldades de adaptação apresentadas quando confrontados com a realidade brasileira. Esse é um contraponto apresentado para a proposição de Almeida e Chaves (2015), pois, a Europa passou pelo Processo de Bolonha, que unificou o sistema de ensino, enquanto no Brasil há uma diversidade de formatos e de modelos de universidade a ser considerada.

O Observatoire National de la Vie Étudiante - OVE - francês tem como público alvo os estudantes matriculados nas IES, sejam eles alunos de escolas técnicas, de graduação ou de pós-graduação. Esse modelo guarda semelhanças com o Censo da Ensino superior desenvolvido pelo Inep, diferenciando-se pelo fato de que, no Brasil, são as instituições que coletam e prestam as informações para o sistema, ao passo que o OVE está associado a uma antiga tradição francesa de produção de estatísticas sobre o percurso escolar dos estudantes.

O questionário aplicado aos estudantes pelo OVE aborda os seguintes temas principais: percurso do estudante até o momento da pesquisa; condições de estudo, estruturais e acadêmicas; tempo livre; trabalho remunerado; habitação; recursos e despesas; saúde; alimentação; situação familiar; características sociodemográficas, como origens sociais e geográficas, sexo, idade, entre outros. A pesquisa é realizada a cada três anos, de março a junho, período considerado pelos especialistas como o mais favorável para obter melhores índices de resposta (Ove, 2018).

A França também conta com o Centre D'études et de Recherches sur les Qualifications - Céreq -, criado em 1971, órgão público que atua sob a supervisão conjunta do Ministério da Educação e Pesquisa e do Ministério do Trabalho, Emprego e Saúde. Nos quase 50 anos de atividade esse Centro se debruça sobre questões relacionadas com o papel da educação inicial e continuada em cursos profissionais; com a integração profissional dos jovens; e com a evolução do mercado de trabalho, das habilidades e das qualificações requeridas (Paul, 2015; Céreq, 2018).

O centro tem como principal função a realização de pesquisas e a sistematização de informações para subsidiar a elaboração de políticas públicas e a tomada de decisões em nível regional, nacional e internacional nas áreas de educação e treinamento profissional, desenvolvendo conhecimentos sobre as ligações entre formação, trabalho e emprego. 
Também faz parte de sua missão aconselhar, acompanhar e equipar os atores na criação de sistemas de avaliação ou monitoramento. Seu público-alvo é diversificado, contemplando agentes públicos e autoridades, parceiros sociais, setores profissionais, organizações trabalhistas e demais atores das áreas de educação e emprego (Céreq, 2018).

O Céreq atua em parceria com laboratórios de pesquisa universitária e com o Centro Nacional de Pesquisa Científica - CNRS - e tem como principais temas de pesquisa a transição da escola para o trabalho, as mudanças nas ocupações e nas qualificações, a qualificação e o treinamento ao longo da carreira e a orientação e o acompanhamento profissional (Céreq, 2018).

Acerca da Alemanha, Paul (2015) e Almeida e Chaves (2015) destacam a adoção de um sistema de acompanhamento de egressos baseado em um projeto de cooperação interuniversitário, criado pelo International Centre for Higher Education Research Kassel Incher-Kassel, denominado Kooperationsprojekt Absolventenstudien - Koab. Segundo informações coletadas na página do projeto cooperativo 'estudantes e graduados Koab', esse centro de estudos com egressos iniciou em 2007, sob a coordenação do IncherKassel, e permaneceu até 2017. Desde meados de 2017 a coordenação de novos estudos foi transferida para um spin-off do Incher, o Institut für Angewandte Statistik - Istat -, que passou a oferecer um projeto idêntico.

O Istat tem como finalidade ofertar para as universidades uma gama de pesquisas científicas sobre o ciclo de vida dos alunos, focando nas diversas nuanças da avaliação da educação superior, da avaliação dos estudantes, dos professores, das instituições, dos programas de pós-graduação, entre outros aspectos. Por meio do projeto Koab cerca de 70.000 graduados de universidades alemãs foram entrevistados, aproximadamente, 1,5 anos após completarem seus estudos e sua carreira profissional. Outra pesquisa ocorre em mais ou menos quatro a cinco anos após a graduação. As segundas pesquisas ainda estão sendo realizadas em cooperação entre o Incher e o Istat, enquanto as novas pesquisas são operacionalizadas apenas pelo Istat (Istat, 2018; Incher-Kassel, 2018).

As pesquisas são conduzidas em cooperação entre, aproximadamente, as 60 universidades parceiras na Alemanha e a equipe Koab. Cada universidade parceira teve a oportunidade de complementar o questionário central, que é vinculativo para todas as universidades, com perguntas individuais. Além disso, as universidades parceiras são amparadas com serviços intensivos de aconselhamento, incluindo numerosos eventos e workshops. Os resultados gerais das pesquisas realizadas são publicados na página do projeto e disponibilizados para cada uma das escolas intervenientes divulgarem os dados específicos da sua instituição. Esse projeto conta com o apoio do Ministério Federal de Educação e Pesquisa e já serviu de referência para a implantação de sistemas avaliativos em mais de 30 países europeus (Istat, 2018; Incher-Kassel, 2018).

As principais publicações encontradas na página do projeto Koab se referem à temas como a transição dos graduados para o mercado de trabalho; as condições de trabalho dos pós-graduados; a situação ocupacional dos egressos; a continuidade dos estudos e ingresso na vida acadêmica; a mobilidade internacional de estudantes de pósgraduação; a avaliação e revisão do instrumento de coleta de dados; os percursos 
profissionais e acadêmicos; as questões de gênero na vida acadêmica e profissional; a avaliação da formação superior e do corpo docente; o alinhamento entre a formação universitária e o mercado de trabalho, entre outras (Incher-Kassel, 2018).

A experiência da Universidade de Kassel denota que a preocupação do projeto Koab está relacionada especialmente à ensino superior e ao mundo do trabalho, já que a principal meta é manter um alinhamento entre uma formação de qualidade e as expectativas e necessidades da economia alemã, de modo que os estudantes sejam absorvidos pelo mercado de trabalho e se destaquem em seu campo de atuação.

Ao trazer esses modelos para o contexto do sistema educacional brasileiro observase que o Brasil ainda não possui uma política pública de acompanhamento de egressos que permita a captação e a sistematização de informações integradas sobre esse público. Os autores Almeida e Chaves (2015) apresentam a necessidade de definição de sistemas, instrumentos e critérios para acompanhar a inserção profissional dos diplomados e recorrem aos sistemas internacionais de coleta de informações para fundamentar sua proposição. Na mesma linha Paul (2015) apresenta esses sistemas como referência para o acompanhamento de egressos, comparando-os com a realidade brasileira.

No Brasil os dados do Censo da Educação Superior são a principal fonte de informações sobre o perfil do alunado. Essas informações são utilizados para as projeções dos índices de evasão e conclusão (Hoffmann; Nunes; Muller, 2019), mas não avançam no estabelecimento de medidas de controle dos índices e de avaliação das causas, motivos e fatores que interferem no desempenho acadêmico e na motivação dos alunos para concluírem seus estudos. Além disso, os dados do censo dedicam-se a reunir informações sobre o percurso dos estudantes, sem a pretensão de se estender ao acompanhamento dos diplomados.

\section{Práticas de acompanhamento de egressos adotadas em universidades públicas brasileiras}

A preocupação com o destino dos egressos no ensino superior brasileira passou a ser registrada a partir da estruturação dos sistemas avaliativos. Um dos primeiros estudos sobre a trajetória acadêmica e profissional dos alunos foi realizado por Schwartzman e Castro (1991) na Universidade de São Paulo. Posteriormente, Castro (2003) destacou que dentre as instituições brasileiras apenas a USP possuía estudos prontos sobre o acompanhamento de egressos, mas não referenciou esses supostos estudos.

A implantação do Sinaes, em 2004, inseriu os egressos no processo de avaliação. Os egressos integram a nona dimensão avaliativa prevista no art. $3^{\circ}$ da lei n. 10.861 , de 14 de abril de 2004, 'Políticas de atendimento aos estudantes'. Desde então as IES brasileiras passaram a desenvolver ações isoladas de acompanhamento de egressos. Apesar de o Sinaes ter atribuído um peso considerável ao indicador egressos na avaliação institucional, a implantação de políticas com essa finalidade não é uma obrigatoriedade. As iniciativas observadas no Brasil partem das próprias instituições que desejam obter melhores índices de qualidade e galgar melhores resultados na avaliação do Inep. 
Almeida e Chaves (2015) observam que "dentro do pequeno universo de estudos já realizados no Brasil acerca da inserção profissional dos diplomados é difícil encontrar abordagens que ultrapassem os limites do contexto local (instituição, curso, etc.) onde foram produzidos" (p. 72). Com relação à inserção dos egressos no processo de avaliação institucional, os estudos são ainda mais escassos. Em âmbito nacional foi encontrada apenas uma abordagem realizada pelo Inep em 2014, na qual o órgão buscou explorar os relatórios de autoavaliação institucional elaborados pelas comissões próprias de avaliação das universidades para verificar as políticas de acompanhamento de egressos neles contidas. O estudo reconhece que as pesquisas realizadas no Brasil se restringem a análises da trajetória dos egressos de algum curso em específico, ao passo que as metodologias e as ações de acompanhamento desse segmento ainda são temas pouco explorados (Inep, 2015).

Diante dessa conjuntura a maneira encontrada para verificar empiricamente práticas de acompanhamento de egressos no contexto brasileiro foi consultar as páginas de instituições que já desenvolvem esse tipo de ação. Partindo do princípio que o egresso é alguém que já concluiu os seus estudos e, portanto, está fora da instituição, pressupõe-se que as ações de acompanhamento de egressos precisam estar publicizadas no site institucional. Em incursões realizadas nos sites de algumas universidades públicas, durante os anos de 2016 e 2017, foram analisadas as descrições das ações de acompanhamento de egressos desenvolvidas, com o propósito de conhecer suas práticas.

O Portal do egresso é um canal de relacionamento interativo disponibilizado no sítio eletrônico da IES, no qual os egressos são convidados a se cadastrar e a continuar participando ativamente da vida institucional após a diplomação. A primeira fase da coleta de dados nos sites das universidades ocorreu em novembro de 2016 e a conclusão da coleta de dados nesses espaços ocorreu em novembro de 2018.

As universidades escolhidas para compor a análise descritiva foram a USP, pioneira na publicação de estudos com egressos no país (Schwartzman; Castro, 1991), a Universidade de Brasília, pioneira na construção de um Portal do Egresso (UnB, 2018a) e referência na coleta de informações sobre a empregabilidade dos egressos (UnB, 2018b); a Universidade Estadual Paulista - Unesp - pelo destaque, assim como a UnB, na oferta de serviços e benefícios aos graduados; e a Universidade do Estado de Santa Catarina Udesc -, que aderiu ao Sinaes e está com sua política de acompanhamento de egressos.

A USP é considerada como referência no acompanhamento de egressos por ser uma das pioneiras na realização desse tipo de pesquisa. Desde 2016 conta com um Portal do egresso estruturado, o AlumniUSP, onde os egressos podem se cadastrar e encontrar contatos, oportunidades de trabalho, educação continuada, entre outros serviços, como acesso ao acervo institucional, cadastro de e-mail no domínio @alumni.usp.br e emissão de diploma digital. Disponibiliza notícias exclusivas sobre os egressos, espaço com vídeos e e-mail para contato. Esse espaço é baseado no acolhimento dos ex-alunos, no relacionamento entre a USP e seus diplomados e em uma relação de troca de experiências entre os próprios egressos (USP, 2018a).

A alusão ao acompanhamento de egressos é mencionada no relatório de autoavaliação com ênfase para o perfil esperado do egresso de cada curso/unidade administrativa e para a inserção dos egressos no mundo do trabalho. A avaliação 
institucional na USP ocorre por ciclos. Os relatórios mais recentes publicados se referem ao quarto ciclo avaliativo que corresponde ao período entre 2010 e 2014. O quinto ciclo referente aos anos de 2017 a 2021 ainda não foi concluído e não apresenta dados publicados. Como os dados publicados são anteriores ao lançamento do Portal do Egresso, a falta de informações precisas sobre esse público é um ponto relatado como fragilidade. A criação do portal é mencionada no relatório de autoavaliação como um projeto que permitirá avançar no monitoramento e no acompanhamento desse público. Algumas unidades realizam pesquisas e/ou possuem iniciativas isoladas de captação de informações, as quais também são apontadas pelos avaliadores como ações recentes (USP, 2018b). Isso indica que o impacto da criação do sistema de acompanhamento de egressos AlumniUSP ainda não foi contemplado na avaliação institucional, o que poderá se concretizar na conclusão do quinto ciclo avaliativo (USP, 2018b).

A UnB publicou a sua primeira pesquisa sobre a empregabilidade dos egressos em 2013, explorando dados da Relação anual de informações sociais do ministério do trabalho e emprego (Rais/MTE). Esses dados são cruzados com o CPF dos ex-alunos e armazenados em seu sistema interno. Segundo informações constantes na página da CPA, essa pesquisa fornece informações sobre a localização do egresso, o tipo de vínculo empregatício, a classificação da ocupação e a renda média (UnB, 2018b).

Esse levantamento permite conhecer a realidade de trabalho dos ex-alunos e estabelecer o nível de relacionamento entre o curso realizado e o enquadramento ocupacional. Após o primeiro estudo foram realizadas novas pesquisas, estratificadas por curso e publicadas em 2016, 2017 e 2018 (UnB, 2018b). Alguns cursos, como Administração e Ciências Contábeis, foram objeto de estudo em dois anos seguidos (2016 e 2017), enquanto os demais foram pesquisados durante um dos três anos. $O$ método de pesquisa empregado considera a evolução das condições laborais dos egressos num intervalo de cinco anos, por meio de uma abordagem longitudinal, permitindo comparar o progresso dos diplomados com os ex-alunos - evadidos ou desligados - e com os profissionais da área atuando na mesma região geográfica e evidenciar o impacto do diploma e da formação ofertada na UnB (UnB, 2018b).

Com relação ao Portal do egresso esse espaço é gerido e mantido pela associação de alunos egressos, a AlumniUnB. A partir de 2016 a associação atualizou completamente a sua página na internet e realizou várias mudanças administrativas. A mensalidade cobrada dos associados passou de $R \$ 80,00$ para $R \$ 10,00$; os serviços e os benefícios oferecidos aos egressos para instigar o cadastramento no portal e a adesão à associação, como acesso à biblioteca, descontos em serviços e aluguel de espaços, foram atualizados e permanecem ativos. Percebe-se que os objetivos da associação não estão relacionados ao levantamento e difusão de informações sobre os egressos. Não há publicações de informações sobre o perfil do egresso ou sobre egressos de destaque na página, mas os associados têm acesso a canais de interação e networking com os colegas (UnB, 2018a). A AlumniUnB atua como uma entidade independente da gestão universitária, cujo foco é a integração e o relacionamento entre os diplomados.

A experiência da UnB denota a falta de alinhamento entre as ações realizadas pela AlumniUnB e a avaliação do ensino ofertado, uma vez que a associação não atua no acompanhamento de egressos, apesar de possuir um canal de relacionamento estruturado, que poderia estar habilitado para isso. Contudo, os esforços realizados pela 
CPA para coletar informações sobre as condições de trabalho dos egressos demonstram a preocupação da universidade em se manter próxima das demandas da sociedade e do sistema econômico. A publicação dessas informações mostra que a universidade preza por uma formação condizente com as demandas do campo profissional.

Considerando que a rede de ex-alunos da UnB é composta de, aproximadamente, oito mil pessoas e que, ao longo de sua história, a instituição já formou em torno de 80 mil pessoas, é possível inferir que, ao estabelecer uma conexão entre a associação e a avaliação institucional, surgirá oportunidade de obter uma diversidade maior de dados sobre o perfil do egresso, suas condições de vida, a evolução profissional e acadêmica e a percepção que eles têm sobre a formação recebida na universidade (UnB, 2018a; UnB, 2018b).

A Unesp, por sua vez, contava em 2016 com uma plataforma denominada Sempre Unesp, a qual se destacava entre as demais instituições na oferta de serviços e benefícios aos ex-alunos cadastrados. Em 23 de julho de 2018 foi lançada uma nova versão da plataforma, o Alumni Unesp como uma atualização do portal Sempre Unesp. De acordo com informações coletadas no portal esse espaço busca reconectar os egressos à universidade para que a instituição continue colaborando com a trajetória dos alunos após a sua formação (Unesp, 2018a).

A instituição informa em sua página que o Portal do egresso foi desenvolvido para atender às demandas dos ex-alunos da graduação e da pós-graduação da Unesp e conta com diversas funcionalidades que exigem o cadastramento do egresso no site. Em pouco mais de dois meses, o Alumni Unesp já registrou mais de seis mil ex-alunos cadastrados. Conforme dados disponibilizados pela equipe de gestão do portal, em 15 de outubro de 2018, a plataforma já tinha registrado 6.464 usuários (Unesp, 2018a).

Além do relacionamento outra preocupação do Alumni Unesp é a divulgação de vagas de emprego. A aba 'Oportunidade', que já existia no portal Sempre Unesp, foi remodelada de modo a atender duas possíveis demandas da rede de ex-alunos: a contratação de profissionais formados pela Unesp e a facilitação da busca de trabalho. Como relatado no portal essa ferramenta conecta os ex-alunos que possuem um negócio próprio ou são de áreas de recursos humanos e quem está à procura do primeiro emprego ou de uma recolocação no mercado de trabalho. Os egressos que são empresários podem divulgar vagas de suas empresas quando preenchem um formulário disponível no ícone 'Tenho uma empresa: cadastrar'. Essa funcionalidade não se restringe apenas aos egressos da Unesp, de modo que outras empresas e interessados também podem oferecer oportunidades para os ex-alunos da universidade por meio da opção 'Empresas'. Os egressos interessados em ocupar as vagas podem utilizar esse recurso clicando em "Visualizar oferta de vagas" e, então, terão acesso ao banco de dados sobre as oportunidades disponíveis no portal (Unesp, 2018a).

Uma vantagem que a Unesp passou a ofertar aos egressos em 2018 é o acesso à biblioteca online da instituição. A solicitação de documentos online por meio da aba 'Serviços' também é outra novidade. Permanecem disponíveis ainda a divulgação de notícias da universidade para os egressos, a divulgação de informações sobre o mercado de trabalho e programas de pós-graduação, as histórias de sucesso, a rede de contatos com os demais ex-alunos, entre outros benefícios (Unesp, 2018a). 
Um dos motivos de ressaltar essa experiência foi que, em 2016, a instituição destacava em seu portal do egresso que se beneficiava das informações prestadas pelos ex-alunos para a avaliação de cursos e a avaliação institucional. Para confirmar essa informação, foi consultado o relatório de autoavaliação institucional da universidade referente ao período entre 2010 e 2014, a última versão encontrada, na qual se observou que houve a aplicação de um questionário aos egressos de pós-graduação, no qual foram levantados os índices de empregabilidade. O documento da CPA informa que "o destino dos egressos é considerado pela Unesp como um fator muito importante para que se possa propor ações de melhoria e aperfeiçoamento de suas atividades" (Unesp, 2018b, p. 42). O que refletiu na criação de um grupo de trabalho formado pelas Pró-reitorias de Graduação, Pós-graduação e Extensão, a fim de avaliar estratégias para obter e melhorar a qualidade dessas informações. Acredita-se que o reflexo desse trabalho seja contemplado no próximo relatório de autoavaliação que será publicado, referente ao quinquênio 2015-2019.

A Udesc está com o Portal do egresso em organização, o que permitiu verificar a evolução das ações relacionadas ao acompanhamento de egressos. Em 2017 as ações de acompanhamento de egressos da instituição partiam de iniciativas realizadas no âmbito de cada centro de ensino. Na página há links que direcionam para esses espaços, possibilitando observar diferentes abordagens, como a divulgação de fotos e informações sobre eventos, listagem de alunos formados no respectivo centro e formulário para cadastramento dos ex-alunos do centro. Não havia uma política integrada de acompanhamento de egressos, apenas a informação de que uma comissão de gestores fora nomeada para colocar em discussão a construção de um projeto institucional voltado aos egressos.

Ao visitar a página para verificar o progresso da iniciativa, constatou-se que a página foi atualizada, contudo, ela registra que "a universidade passará a contar com uma política institucional de egresso" (Udesc, 2018). Isso evidencia que esse projeto ainda não está concluído, pois a frase remete a uma ação futura. Mesmo assim, diversas ações que integrarão essa política já são informadas na página, como o programa de acompanhamento do egresso, a implantação de mecanismos para conhecer o seu perfil profissional, a criação de um canal de comunicação permanente e a organização de eventos. No relato também consta o objetivo de criar um canal direto com os ex-alunos para informar o que está acontecendo na universidade, como eventos, ações e pesquisa, e para contar com o auxílio desse público no desenvolvimento da instituição. A criação de uma rede profissional para promover network entre os egressos também é mencionada como uma ferramenta para a troca de oportunidades de emprego e encontro de parceiros comerciais ou artísticos dentro da própria universidade. Podem se cadastrar no portal todos os diplomados dos cursos de graduação e de pós-graduação da instituição. A consulta de egressos da graduação com algumas informações básicas, como ano de ingresso e de formatura e o centro em que se formou, já está disponível no site (Udesc, 2018).

Ao direcionar para a área de estágios o Portal de empregos conta com a publicação de vagas de emprego e de estágios abertas ao público, o que não restringe o acesso à informação aos egressos cadastrados no Portal do egresso. Isso enfraquece a política de acompanhamento de egressos, pois o cadastramento é indispensável para viabilizar a 
captação de informações estratégicas para a gestão da universidade. Do mesmo modo, as outras abas disponíveis no portal remetem a páginas de outros setores da instituição, sem explicar qual seria o atendimento dispensado de forma diferenciada para os egressos.

Ao consultar o relatório de autoavaliação institucional referente ao período entre 2012 e 2015, constatou-se que o Portal do egresso foi criado ainda em 2011, mas o sistema é limitado à inserção de informações do egresso, portanto, sem interatividade. As informações coletadas são repassadas à Secretaria de Comunicação. No relatório da CPA não foram apresentados dados sobre o perfil do egresso ou sobre suas percepções com relação à universidade, mas a preocupação da comissão com a criação de uma política de acompanhamento de egressos é notória. Além da adoção dessa política institucional, consta entre as recomendações da CPA a criação de um núcleo de acompanhamento dos egressos com o intuito de obter informações para o planejamento de cursos de graduação e de pós-graduação; a avaliação e a sistematização das informações do Portal do Egresso e o encaminhamento destas às direções de ensino; e a possibilidade de mudanças nos cursos a partir da perspectiva dos egressos. Além disso, no site, ressaltase a necessidade de desenvolver um programa de retorno de egressos de cursos de graduação para atualização de conteúdos e divulgar os cursos e eventos aos egressos, ações consideradas ainda insipientes (Udesc, 2015).

Os resultados da consulta aos portais do egresso mostram que parte das IES brasileiras reconhece a importância e tem interesse em coletar dados sobre os seus diplomados, mas as IES ainda não possuem uma política de acompanhamento de egressos ou estão com a organização de suas propostas em estágio inicial. As IES ainda não sabem quais dados precisam ser coletados, nem o que pode ser feito com os dados obtidos, algumas até mencionaram possuí-los, mas não os analisaram ou utilizaram como fonte de informações estratégicas para a gestão (Inep, 2015).

A consecução desta proposta depende da elaboração de uma política pública para a gestão dos egressos do ensino superior no Brasil, pois, apesar de a coleta e a divulgação de informações sobre os diplomados ser uma prerrogativa do processo avaliativo coordenado pelo Sinaes, ainda não existem parâmetros definidos para direcionar a concretização dessas ações no interior das instituições, além disso, as dificuldades em implantá-las são perceptíveis.

No estágio atual a falta de instrumentos para exploração dos dados coletados junto aos egressos em nível interinstitucional, regional ou setorial impede, entre outras possibilidades, a realização de análises socioeconômicas por área geográfica ou por segmento econômico relacionando com as respectivas áreas de formação. A opinião dos egressos é fundamental para direcionar ações de planejamento estratégico e de marketing institucional e para obter uma avaliação consistente, baseada não apenas em dados quantitativos e produtivistas, mas para conhecer o impacto que a universidade efetivamente exerce na vida de seus diplomados. 


\section{Considerações finais}

O sistema educacional brasileiro ainda carece de diretrizes e metodologias para a captação de informações sobre os egressos do ensino superior. Isso tem dificultado a realização de ações sistematizadas de acompanhamento desse público tão importante para a avaliação da qualidade do ensino ofertado e do impacto da formação acadêmica para a sociedade.

As experiências internacionais consultadas demonstraram que a criação de instrumentos para a coleta de informações sobre os egressos dos cursos superiores em nível nacional permite avançar conceitual e metodologicamente nesse campo por meio da realização de uma diversidade de análises técnicas e novos estudos científicos.

Um passo importante para a construção de uma política pública para o acompanhamento de egressos é a realização de um estudo em nível macro, com o propósito de levantar as informações que precisam ser coletadas por todas as IES brasileiras. Com base nessas informações, é possível elaborar um documento com instruções para criar um inquérito padronizado que deverá ser aplicado em todas as IES integrantes do Sinaes, sob a supervisão do Inep.

A análise de uma pequena amostra das universidades brasileiras demonstrou que 0 acompanhamento de egressos é recente, que ainda está sendo estruturado e que a sua finalidade e importância não estão consolidadas, o que reflete na dificuldade que a gestão universitária possui em conceber o acompanhamento de egressos a partir da ótica da avaliação institucional. As CPAs encontram caminhos alternativos para responder aos questionamentos do Sinaes acerca dos diplomados, que nem sempre estão vinculados ao Portal do egresso, ferramenta crucial para esse tipo de abordagem. Ao orientar as instituições nesse sentido, o Inep pode acender a esse entendimento e instigar as IES a investirem em canais de relacionamento com a sociedade, uma vez que os egressos são a melhor representação desse segmento no interior da universidade.

A interação com os diplomados amplia o leque de estratégias para captação de informações, enriquecendo a gestão universitária e a qualidade da formação acadêmica. A ação dos gestores e das instâncias governamentais responsáveis pelo segmento educacional é fundamental nesse contexto, conforme pode ser constatado nos modelos europeus, vinculados e supervisionados pelos ministérios da educação e do trabalho.

Para a concepção do acompanhamento de egressos como uma política pública de avaliação educacional é necessário que seja realizada uma reformulação no modelo de avaliação voltado aos egressos preconizado pelo Sinaes, tornando obrigatória a coleta e a divulgação de informações sobre o perfil dos diplomados, os seus níveis de empregabilidade, a avaliação do curso e da instituição, entre outras questões importantes para direcionar as ações de gestão das IES. Sem essa prerrogativa os desafios para a inserção definitiva do tema na agenda de gestão do ensino superior continuarão evidentes, assim como as iniciativas das instituições tendem a não se tornar perenes e consistentes.

\section{Referências}

ALMEIDA, Rachel de Castro; CHAVES, Miguel. Inserção profissional de diplomados: uma incursão por estudos e instrumentos metodológicos internacionais. Revista Crítica e Sociedade, Uberlândia, v. 5 n. 2, 2015, p. 56-78. 
BAGGI, Cristiane Aparecida dos Santos; LOPES, Doraci Alves. Evasão e avaliação institucional no ensino superior: uma discussão bibliográfica. Avaliação, Campinas, v. 16, n. 2, 2011, p. 355-374.

BRASIL. Constituição da República Federativa do Brasil de 1988. Brasília: Senado Federal, 1988.

BRASIL. Decreto n. 6.096, de 24 de abril de 2007: institui o Programa de Apoio a Planos de Reestruturação e Expansão das Universidades Federais - Reuni. Disponível em: http://www.planalto.gov.br/ccivil_03/_Ato2007-2010/2007/Decreto/D6096.htm Acesso em: 02 mai. 2019.

BRASIL. Lei n. 9.394, de 20 de dezembro de 1996: estabelece as diretrizes e bases da educação nacional. Disponível em: http://www.planalto.gov.br/ccivil_03/Leis/L9394.htm. Acesso em: 12 nov. 2018.

BRASIL. Lei n. 10.260, de12 de julho de 2001: dispõe sobre o Fundo de Financiamento ao estudante do Ensino Superior e dá outras providências. Disponível em: http://www.planalto.gov.br/ccivil_03/LEIS/LEIS_2001/L10260compilado.htm. Acesso em: 12 nov. 2018.

BRASIL.Lei n. 10.861, de 14 de abril de 2004: institui o Sistema Nacional de Avaliação da Ensino superior e dá outras providências. Disponível em: http://www.planalto.gov.br/ccivil_03/_ato2004-2006/2004/lei//10.861.htm. Acesso em: 17 set. 2018.

BRASIL. Lei n. 11.096, de 13 de janeiro de 2005: institui o Programa Universidade para Todos, regula a atuação de entidades beneficentes de assistência social no ensino superior; altera a Lei $n^{\circ}$ 10.891, de 9 de julho de 2004, e dá outras providências. Disponível em: http://www.planalto.gov.br/ccivil_03/_ato2004-2006/2005/lei/l11096.html. Acesso em: 12 nov. 2018.

BRASIL. Lei n. 12.711, de 29 de agosto de 2012: dispõe sobre o ingresso nas universidades federais e nas instituições federais de ensino técnico de nível médio e dá outras providências. Disponível em: http://www2.camara.leg.br/legin/fed/lei/2012/lei12711-29-agosto-2012-774113-publicacaooriginal-137498-pl.html. Acesso em: 12 nov. 2018.

BRASIL. Lei n. 13.005, de 25 de junho de 2014: aprova o Plano Nacional de Educação - e dá outras providências. Disponível em: http://www.planalto.gov.br/ccivil_03/_Ato20112014/2014/Lei/L13005.htm. Acesso em: 16 nov. 2019.

CÉREQ - CENTRE D'ÉTUDES ET DE RECHERCHES SUR LES QUALIFICATIONS. Disponível em http://www.cereq.fr/index.php/cereq. Acesso em 13 nov. 2018.

HOFFMANN, Ivan Londero; NUNES, Raul Ceretta; MULLER, Felipe Martins. As informações do censo da ensino superior na implementação da gestão do conhecimento organizacional sobre evasão. Gestão \& Produção, São Carlos, v. 26 n. 2, 2019, p. 1-14.

INCHER-KASSEL - DAS INTERNATIONAL CENTRE FOR HIGHER EDUCATION RESEARCH KASSEL. Disponível em https://www.unikassel.de/einrichtungen/incher/ueber-incher.html. Acesso em 13 nov. 2018.

INEP. Censo da educação superior. Disponível em: http://portal.inep.gov.br/censo-daeducacao-superior. Acesso em 17 abr. 2020.

INEP. Política institucional de integração e de avaliação do egresso na melhoria da IES: Sistema Nacional de Avaliação da Ensino superior - Sinaes. Brasília: Inep, 2015. 
INEP. Censo da educação superior 2018: notas estatísticas. Disponível em: http://download.inep.gov.br/educacao_superior/censo_superior/documentos/2019/censo_d a_educacao_superior_2018-notas_estatisticas.pdf. Acesso em: 17 abr. 2020.

ISTAT - INSTITUT FÜR ANGEWANDTE STATISTIK. Disponível em http://www.istat.de/de/studierendenbefragung.html. Acesso em 13 nov. 2018.

KOAB - KOOPERATIONSPROJEKT ABSOLVENTENSTUDIEN. Disponível em: https://www.uni-kassel.de/einrichtungen/incher/forschung/studierende-und-

absolventinnen/kooperationsprojekt-absolventenstudien-koab.html. Acesso em: 13 nov. 2018.

LOUSADA, Ana Cristina Zenha; MARTINS, Gilberto de Andrade. Egressos como fonte de informação à gestão dos cursos de Ciências Contábeis. Revista Contabilidade e Finanças, São Paulo, v. 16, n. 37, 2005, p. 73-84

MEC. Planejando a próxima década: conhecendo as 20 metas do Plano Nacional de Educação. $2014 . \quad$ Disponível em http://pne.mec.gov.br/images/pdf/pne_conhecendo_20_metas.pdf. Acesso em: 16 nov. 2018.

MELO, Danilo; SERVA, Maurício. A agenda do professor-pesquisador em Administração: uma análise baseada na sociologia da ciência. Cad. EBAPE.BR, Rio de Janeiro, v. 12, n. 3, 2014.

OVE - OBSERVATOIRE NATIONAL DE LA VIE ÉTUDIANTE. Disponível em http://www.ove-national.education.fr/. Acesso em 13 nov. 2018.

PAUL, Jean Jaques. Acompanhamento de egressos do ensino superior: experiência brasileira e internacional. Caderno CRH, Salvador, v. 28, n. 74, 2015, p. 309-326.

PAULA, Maria de Fátima Costa de. Políticas de democratização da ensino superior brasileira: limites e desafios para a próxima década. Avaliação, Campinas, v. 22, n. 2, 2017, p. 301-315.

RISTOFF, Dilvo. Democratização do campus: impacto dos programas de inclusão sobre o perfil da graduação. Rio de Janeiro: Uerj, 2016.

RISTOFF, Dilvo. Os desafios da ensino superior na lbero-América: inovação, inclusão e qualidade. Avaliação, Campinas, v. 18, n. 3, 2013, p. 519-545.

SILVA, José Marcos; BEZERRA, Roque Oliveira. Sistema de acompanhamento dos egressos aplicado na Universidade Federal de Santa Catarina. Revista GUAL, Florianópolis, v. 8, n. 3, 2015, p. 1-15.

SCHWARTZMAN, Simon; CASTRO, Maria. Helena de Magalhães. A trajetória acadêmica profissional dos alunos da USP. São Paulo: USP, s/d. Disponível em: <http://nupps.usp.br/downloads/docs/dt9102.pdf>. Acesso em 3 maio 2019.

TERRA, Ricardo. A universidade entre a excelência administrada e o social desenvolvimentismo. Novos Estudos Cebrap, São Paulo, n. 100, 2014, p. 81-95.

UDESC. AlumniUDESC, Portal do egresso. Disponível em https://www.udesc.br/alumni. Acesso em 16 nov. 2018.

UDESC. Relatório de autoavaliação institucional 2012-2015. Disponível em https://www.udesc.br/arquivos/udesc/documentos/Relat_rio_de_Autoavalia_o_Institucion al_2012_2015_14861292834807.pdf. Acesso em 17 nov. 2018.

UNB. AlumniUnB. [2018a]. Disponível em: https://www.alumniunb.com/. Acesso em: 15 nov. 2018. 
UNB. Pesquisa com egressos. [2018b]. Disponível em http://www.cpa.unb.br/index.php?option=com_contentinho\&view=article\&id=447\&ltemid=2 61. Acesso em 15 nov. 2018.

UNESP. Alumni UNESP. [2018a]. Disponível em https://alumni.unesp.br/. Acesso em 16 nov. 2018.

UNESP. Avaliação institucional. [2018b]. Disponível em https://www2.unesp.br/portal\#!/cpa/avaliacao-institucional/. Acesso em 16 nov. 2018.

USP. Alumni USP. [2018a]. Disponível em http://www.alumni.usp.br/. Acesso em 16 nov. 2018.

USP. CPA - Comissão Permanente de Avaliação. [2018b]. Disponível em https://www5.usp.br/reitoria/vice-reitor/cpa-comissao-permanente-de-avaliacao. Acesso em 16 nov. 2018.

Lilian Wrzesinski Simon é estudante no curso de doutorado em Administração na Universidade Federal de Santa Catarina.

Orcid: http://orcid.org/0000-0003-0307-4948.

Endereço: Rua Eng. Agronômico Andrei Cristian Ferreira, s/n, UFSC, Departamento de Ciências da Administração - 88040-900 - Florianópolis - SC - Brasil.

E-mail: lilian.uffs@gmail.com.

Andressa Sasaki Vasques Pacheco é professora no Departamento de Ciências da Administração da UFSC.

Orcid: http://orcid.org/0000-0002-1825-0097.

Endereço: Rua Eng. Agronômico Andrei Cristian Ferreira, s/n, UFSC, Departamento de Ciências da Administração - 88040-900 - Florianópolis - SC - Brasil.

E-mail: andressa.ufsc@gmail.com.

Recebido em 9 de junho de 2020.

Aceito em 20 de setembro de 2020.

(c) (i) $(\$$ 